\title{
Jovens universitários e fatores de risco para infecção pelo HIV: uma revisão de literatura
}

\author{
Young university students and risk factors for HIV infection: a literature
}

\author{
review
}

Jóvenes universitarios y factores de riesgo para la Infección por VIH: una revisión de la literatura

Maria da Graça Corrêa Lopes Wohlgemuth ${ }^{1}$

Dra. Larissa Polejack ${ }^{2}$

Dra. Eliane Seidl ${ }^{3}$

\begin{abstract}
Resumo
Apesar dos esforços realizados no desenvolvimento de estratégias de prevenção da infecção pelo vírus HIV, atualmente a prevalência tem aumentado entre os jovens de 19 a 24 anos. Esta realidade ocorre em vários países e traz preocupações sobre os impactos possíveis nesta geração. O objetivo deste trabalho é realizar uma revisão de artigos publicados sobre fatores de risco que estudantes universitários apresentam relacionados com a infecção pelo HIV. Foram realizadas pesquisas em três bases de dados: BVS, PubMed e SciELO, nos quais foram selecionados artigos com estudos empíricos a partir de 2015. Dos 38 artigos identificados a partir dos operadores booleanos HIV, adultos jovens, fator de risco e universitários, foram selecionados seis, que se adequavam aos critérios de inclusão. Observou-se que o uso de álcool e outras drogas associado a comportamentos sexuais de risco, como o não uso de preservativo, e baixo índice de testagem, ampliam a vulnerabilidade desta população. Concluiu-se acerca da necessidade de que o tema seja amplamente debatido com os estudantes e realizadas ações de promoção de saúde e de prevenção de infecções sexualmente transmissíveis no contexto universitário.
\end{abstract}

Palavras-chave: HIV, estudantes universitários, fatores de risco, testagem, vulnerabilidades.

\begin{abstract}
Despite the efforts made to develop strategies to prevent infection by the HIV virus, currently the prevalence has increased among young people aged 19 to 24 years. This reality occurs in several countries and raises concerns about the possible impacts on this generation. The aim of this work is to review published articles on risk factors that university students have related to HIV infection. Researches were carried out in three databases: VHL, PubMed and SciELO, in which articles with empirical studies from 2015 were selected. Of the 38 articles identified from the Boolean operator's HIV, young adults, risk factor and university students, were selected six, which met the inclusion criteria. It was observed that the use of alcohol and other drugs associated with risky sexual behaviors, such as not using a condom, and a low rate of testing, increase the vulnerability of this population. It was concluded that there is a need for the topic to be widely discussed with students and actions to promote health and prevent sexually transmitted infections in the university context.
\end{abstract}

\footnotetext{
${ }^{1}$ (Maria da Graça Corrêa Lopes Wohlgemuth; Pós-Graduada em Saúde Coletiva; Universidade de Brasília UnB; Brasília, Distrito Federal, Brasil; gracaclw13@gmail.com)

2 (Larissa Polejack; Doutora em Processos de Desenvolvimento Humano e Saúde; Universidade de Brasília UnB; Brasília, Distrito Federal, Brasil; larissapolejack@ @otmail.com)

3 (Eliane Fleury Seidl; Doutora em Psicologia; Universidade de Brasília - UnB; Brasília, Distrito Federal, Brasil; eliane.seidl@gmail.com)
} 
Key words: HIV, university students, risk factors, testing, vulnerabilities.

\section{Resumen}

A pesar de los esfuerzos realizados en el desarrollo de estrategias para prevenir la infección por el virus del VIH, actualmente la prevalencia ha aumentado entre los jóvenes de 19 a 24 años. Esta realidad ocurre en varios países y genera preocupaciones sobre los posibles impactos en esta generación. El objetivo de este trabajo es revisar los artículos publicados sobre los factores de riesgo que los estudiantes universitarios han relacionado con la infección por VIH. Se realizaron investigaciones en tres bases de datos: BVS, PubMed y SciELO, en las que se seleccionaron artículos con estudios empíricos de 2015. De los 38 artículos identificados de los operadores booleanos VIH, adultos jóvenes, factor de riesgo y estudiantes universitarios, se seleccionaron seis, que cumplieron los criterios de inclusión. Se observó que el uso de alcohol y otras drogas asociadas con conductas sexuales de riesgo, como no usar un condón y una tasa baja de pruebas, aumentan la vulnerabilidad de esta población. Se concluyó que es necesario que el tema sea ampliamente discutido con los estudiantes y las acciones para promover la salud y prevenir las infecciones de transmisión sexual en el contexto universitario.

Palabras clave: VIH, estudiantes universitarios, factores de riesgo, pruebas, vulnerabilidades.

\section{Introdução}

Temas referentes ao Vírus da Imunodeficiência Humana (HIV) e à Síndrome da Imunodeficiência Adquirida (aids) são de importância para a saúde pública e precisam ser abordados devido ao aumento dos casos de adultos jovens infectados pelo HIV no Brasil e em diversos outros países. Esse fato vai além de questões que envolvem valores, mas também por questões sociais (BRASIL, 2017). Desde a sua descoberta na década de 1980, o vírus tem sido amplamente estudado, tendo em vista que a aids é uma doença crônica que compromete o funcionamento do sistema imunológico e interfere na capacidade do organismo de se defender contra outras infecções oportunistas.

As formas de transmissão do vírus, já bem conhecidas são: relação sexual desprotegida com pessoa infectada, tanto vaginal, quanto anal ou oral; transfusão de sangue ou compartilhamento de agulhas, seringas ou instrumentos perfurocortantes com sangue infectado; transmissão vertical de mulher gestante soropositiva para o bebê, durante a gestação; parto ou amamentação sem acompanhamento adequado (BRASIL, 2017).

No início da epidemia de aids, os grupos mais afetados foram os homossexuais, usuários de drogas injetáveis e hemofílicos, sendo que com o passar dos anos, mais especificamente na década de 1990, o perfil da epidemia foi se modificando. Surgiu, assim, a necessidade de se construir novas políticas e estudos que atendessem às demandas oriundas do aumento do número de casos por transmissão sexual e do crescimento do número de mulheres infectadas (FERRAZ, 2012). De 1981 a junho de 2017, foram identificados 882.810 casos de aids no Brasil e, segundo o Boletim Epidemiológico (BRASIL, 2017), uma média de 42 mil novos casos foram registrados nos últimos cinco anos. 
Ainda, de acordo com o Boletim Epidemiológico da Secretaria de Vigilância em Saúde do Ministério da Saúde (2018), foram notificados, de 2007 até junho de 2018, no Sistema de Informação de Agravos de Notificação - Sinan, 247.795 casos de infecção pelo HIV no Brasil, sendo 117.415 (47,4\%) na região Sudeste, 50.890 (20,5\%) na região Sul, $42.215(17,0 \%)$ na região Nordeste, $19.781(8,0 \%)$ na região Norte e $17.494(7,1 \%)$ na região Centro-Oeste. Para se visualizar melhor a importância de estudos e aprofundamento sobre esse tema, é necessário analisar dados reais sobre o impacto da epidemia de HIV/aids no Brasil. No ano de 2017, foram notificados 42.420 novos casos de infecção pelo HIV e os números apontam um aumento da taxa de detecção de aids em mulheres. Entre os homens de 15 a 19 anos de idade, no decorrer de 2007 a 2017, a taxa triplicou de 2,4 para 6,9 casos/100 mil habitantes.

Perante esse crescimento, com base em dados epidemiológicos e em estudos diversos sobre a infecção pelo HIV e aids, a partir do trabalho conjunto do Estado brasileiro com representantes de movimentos sociais, gestores, estudiosos e profissionais de saúde, consolidou-se uma rede de atenção em HIV/aids no âmbito do Sistema Único de Saúde (SUS), com serviços qualificados e especializados. Estes serviços se concretizam por meio de um conjunto de práticas, conhecimentos técnicos e de gestão, que buscam garantir a integralidade da atenção, a universalidade e a equidade, viabilizando o acesso à testagem sorológica e ao diagnóstico, bem como à prevenção e ao tratamento.

A busca da consolidação dos princípios do SUS foram fundamentais para que ocorresse a redução da morbimortalidade por aids, a diminuição das taxas de transmissão vertical do vírus e do aumento da expectativa de vida de pessoas que vivem com HIV (BRASIL, 2018).

De acordo com dados do Ministério da Saúde, existe um número maior de casos de adolescentes e jovens adultos vivendo com HIV (BRASIL, 2017). A Organização Mundial da Saúde (OMS) define como Adolescência as idades entre 10 e 19 anos, diferentemente da Organização das Nações Unidas (ONU), que considera adolescentes aqueles indivíduos entre 15 e 24 anos, critério este usado principalmente para fins estatísticos e políticos. Atualmente, por conveniência, agrupam-se ambos os critérios para denominar adolescência e juventude ou adolescentes e jovens. Desse modo, ao reunir as faixas etárias, desde 10 a 24 anos, pode-se afirmar que esse é o grupo preponderante nas escolas e nas universidades, fazendo delas um espaço importante e necessário para intervenções, em especial às promotoras de saúde e preventivas. 
Atualmente, a média de idade de ingresso na universidade é por volta de 18 anos e essa é a população que tem apresentado uma curva crescente na prevalência de novas infecções pelo HIV. Segundo Gil (2016), é necessário que ocorram novos estudos e engajamento científico para saber mais sobre o comportamento sexual de jovens de universidades brasileiras, pois é preciso trabalhar sobre o tema HIV e outras infecções sexualmente transmissíveis nas instituições de ensino. Isso porque universidades e faculdades são espaços que poderão contribuir para a redução de casos em adultos jovens, já que são locais que propiciam a diversidade, o diálogo e a convivência entre estudantes e professores.

A universidade é um ambiente que marca uma etapa e gera mudanças na vida dos jovens, pois comumente, durante o ensino médio, a maioria dos adolescentes ainda residem com suas famílias, possuindo uma rotina mais controlada. Contudo, de um momento para o outro, muitas vezes eles necessitam ir para outras cidades com intuito de dar continuidade aos estudos em nível universitário e, então, passam a viver longe da família, às vezes sozinhos ou com outros universitários. Esse momento passa a ser, para muitos, uma mudança marcante, pois terão que tomar conta de suas vidas, ter responsabilidades que geralmente não tinham anteriormente, em especial por estarem longe do convívio familiar, além de poderem seguir com seu dia a dia como bem entenderem, sem a fiscalização ou pressão dos parentes.

O interesse nesse segmento populacional, com nível mais alto de escolaridade, decorre da reduzida produção de estudos com tal faixa-etária. Esforços preventivos são relevantes junto a esse grupo, pois trata-se de uma questão de saúde pública. Desde 2017, o Ministério da Saúde do Brasil adotou a estratégia da Prevenção Combinada (BRASIL, 2017), que preconiza a necessidade de que sejam utilizadas diferentes estratégias de prevenção de forma conjunta, considerando intervenções biomédicas, comportamentais e estruturais visando redução das vulnerabilidades à infecção pelo HIV.

Dentre as estratégias preconizadas, podemos destacar: acesso a testagem e, caso o resultado seja positivo, o acesso imediato para acompanhamento em serviço de saúde para definição do tratamento antirretroviral; uso de preservativos (masculino ou feminino); o uso de gel lubrificante; tratamento de infecções sexualmente transmissíveis; consulta com médicos para as profilaxias pré-exposição sexual (PrEP) e pós-exposição (PEP) ao HIV, sendo essas algumas das estratégias que podem ser combinadas para melhorar a prevenção (BRASIL, 2017). Nesse sentido, o presente artigo teve por objetivo realizar uma revisão de estudos publicados sobre fatores de risco que estudantes universitários possuem quanto à infecção pelo HIV. 


\section{Método}

Trata-se de um estudo de revisão da literatura científica de artigos empíricos, a partir de pesquisas publicadas sobre HIV. Essa revisão foi norteada pela pergunta: Quais são os fatores de risco que estudantes universitários têm quanto à infecção pelo HIV? Para o levantamento dos artigos, realizou-se uma busca nas seguintes bases de dados: Biblioteca Virtual em Saúde - Psicologia Brasil (BVS- PSI); PubMed; SciELO - Scientific Electronic Library Online. Os descritores foram combinados dois a dois, sendo eles: adultos jovens, universitários, HIV e fator de risco. Foi ainda utilizado o operador booleano AND, e seus respectivos termos em língua espanhola, inglesa e portuguesa. Foi estabelecido que os artigos selecionados deveriam ter sido publicados a partir do ano de 2015, visando a obtenção de literatura mais recente sobre o tema.

Em síntese, os critérios de inclusão utilizados foram: serem artigos escritos a partir de 2015; artigos publicados em inglês, português e espanhol; artigos que abordassem adultos jovens universitários com idade entre 18 a 24 anos; estudos empíricos e o assunto HIV como tema principal. Os critérios de exclusão foram: não ser um trabalho focado no campo universitário; artigos publicados em línguas diferentes que o inglês, português e espanhol; data de publicação inferior a 2015. O resultado da busca nas bases de dados totalizou 38 trabalhos, onde 22 foram excluídos pela análise do título, seis artigos foram excluídos após leitura do resumo, dois após leitura integral e dois por duplicidade (Figura 1).

Por motivos de enquadramento com o tema proposto, foi necessário que ocorresse a exclusão de estudos que não se coadunavam com o assunto estabelecido, tendo em vista que muito se pesquisa sobre HIV/aids, mas pouco se aborda sobre esse tema relacionado à faixa etária de adultos jovens e universitários. 


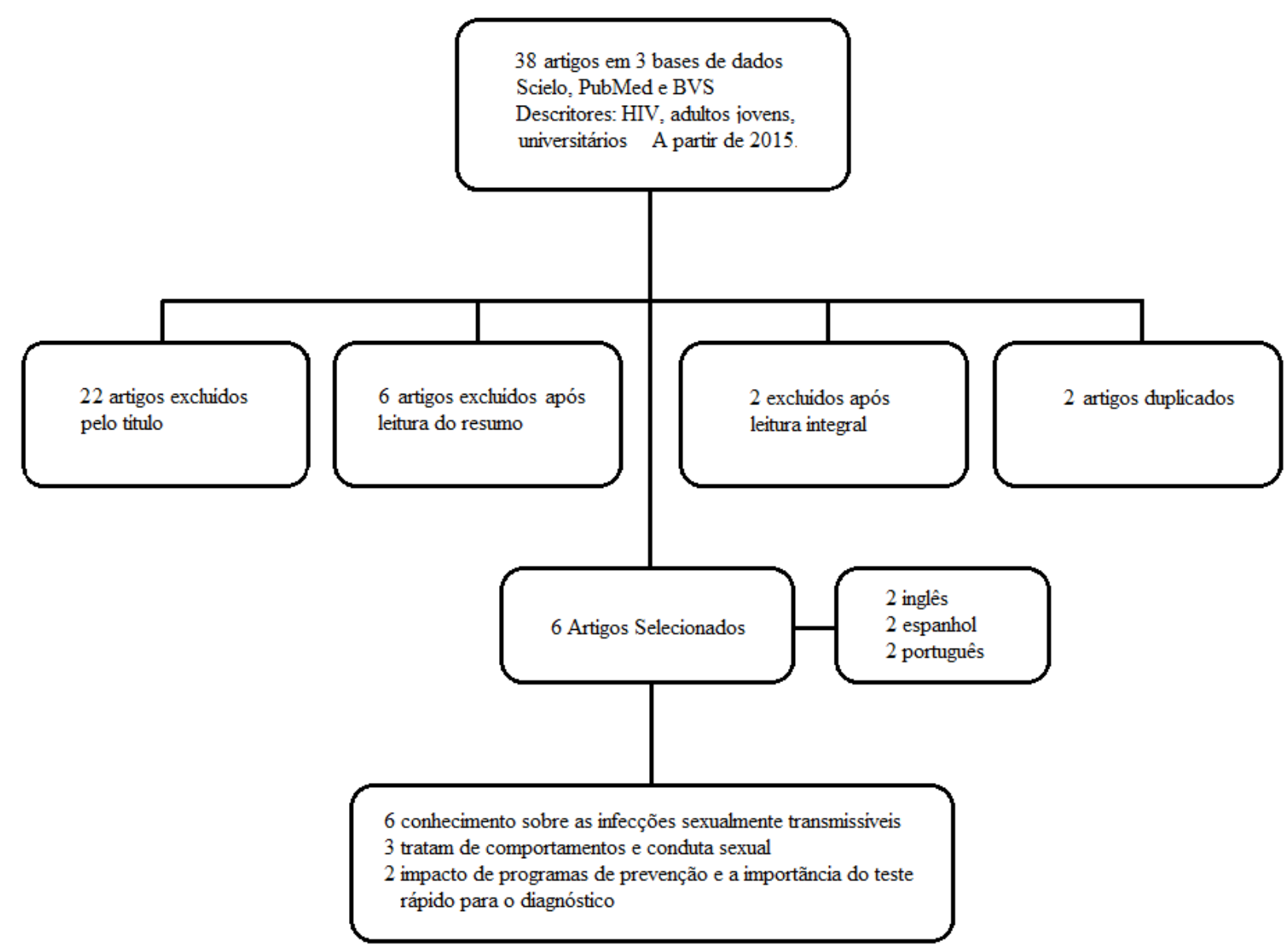

Figura 1 - Fluxograma do processo de busca e identificação dos artigos selecionados Fonte: Desenvolvido pela autora.

Os artigos que foram excluídos pelo título referenciavam não só ao HIV, mas sim a relacionava à outras doenças, como o câncer. Os títulos falavam ainda sobre fatores de risco entre estudantes do ensino médio ao invés de universitários; abordavam questões relacionadas aos jovens e explicitamente sobre sua fertilidade; tratavam sobre medicamentos que influenciavam nos marcadores sanguíneos; não apresentavam no título nenhuma característica que identificasse que o assunto abordado era HIV/aids, universitários, adultos jovens e fatores de risco. Todos esses aspectos levaram à exclusão, tendo em vista que já fugiam ao tema central definido e não se enquadravam na proposta de revisão.

Ocorreu também a exclusão pelos resumos, os quais se diferenciavam do proposto por seus títulos, ou seja, a leitura dos resumos mostrou que aqueles trabalhos não abordavam os assuntos propostos, pois não versavam expressamente sobre HIV e/ou aids em jovens universitários, ou ainda, abordavam esse tema apenas como um aspecto mínimo de outro tema 
distinto. Nos restantes, a leitura na íntegra acarretou a exclusão de textos que fugiram dos objetivos propostos pelas pesquisadoras, por não incluir elementos sobre o assunto pesquisado na estrutura básica de artigo, como na Introdução, na Metodologia, na Discussão e Resultados, ou por não serem artigos empíricos.

O último fator de exclusão foi devido à existência de dois artigos idênticos, mas que foram publicados em duas bases de dados diferentes, o que fez com que, na hora da busca pela pesquisadora, eles fossem identificados mais de uma vez. Assim, ao final se mantiveram seis artigos que, além de conterem em todas as suas partes o foco no tema estabelecido, não possuíam divergências entre os termos utilizados no título, no resumo e no texto, além de se enquadrar na proposta de revisão.

\section{Resultados e Discussão}

Os artigos selecionados abordaram o tema central e aspectos necessários para se compreender os fatores de risco em universitários, além de terem apresentado demasiada importância sobre a realização de testagens. Tais fatores evidenciam a necessidade de que o teste ocorra o mais cedo possível, para que em casos de resultado positivo, o tratamento seja iniciado de forma eficiente e rápida.

Os seis estudos selecionados para a revisão de literatura tratavam do tema HIV/aids em estudantes universitários, pesquisando jovens com idades entre 18 e 24 anos, que estavam no início de seus cursos de graduação. Dos artigos selecionados, todos mencionavam sobre os conhecimentos acerca das infecções sexualmente transmissíveis; três focalizaram comportamento e conduta sexual; dois abordavam o impacto dos programas de prevenção e a importância do teste rápido para diagnóstico (Tabela 1).

Tabela 1 - Artigos Utilizados na Revisão de Literatura

\begin{tabular}{|c|c|c|c|}
\hline Título & $\begin{array}{l}\text { Autores, base de dados e } \\
\text { idioma }\end{array}$ & Método & $\begin{array}{l}\text { Fatores de risco } \\
\text { identificados nos estudos }\end{array}$ \\
\hline $\begin{array}{l}\text { Impacto de um programa } \\
\text { de intervenção educativa } \\
\text { nos comportamentos } \\
\text { sexuais de jovens } \\
\text { universitários. }\end{array}$ & $\begin{array}{c}\text { Oliveira, Caramelo, Patrício, } \\
\text { Camarneiro, Cardoso e Pita } \\
\text { (2017). } \\
\text { SciELO, português }\end{array}$ & $\begin{array}{l}\text { Estudo de coorte prospetivo } \\
\text { /quase-experimental. } \\
\text { Instrumento: questionário } \\
\text { Amostra: } 1303 \text { estudantes } \\
\text { de Coimbra / Portugal }\end{array}$ & $\begin{array}{c}\text { Não uso de preservativo em } \\
\text { relacionamentos ocasionais, } \\
\text { principalmente entre } \\
\text { homens; baixo } \\
\text { conhecimento de ISTs }\end{array}$ \\
\hline $\begin{array}{l}\text { The prevalence of and } \\
\text { factors associated with } \\
\text { willingness to utilize } \\
\text { HTC service among } \\
\text { college students in China }\end{array}$ & $\begin{array}{c}\text { Fu, Shi, Yan, Li, Han, Li... } \\
\text { Wang (2018). } \\
\text { Pubmed, Inglês }\end{array}$ & $\begin{array}{c}\text { Estudo quantitativo } \\
\text { Instrumento: questionário } \\
\text { Amostra: } 3314 \text { estudantes } \\
\text { de Ciências e Tecnologia de } \\
\text { Hubei/China }\end{array}$ & $\begin{array}{c}\text { Discriminação e estigma } \\
\text { para procurar os centros de } \\
\text { testagem; baixo } \\
\text { conhecimento sobre HIV; } \\
\text { baixo índice de testagem }\end{array}$ \\
\hline $\begin{array}{c}\text { Similarities and } \\
\text { Differences Matter: }\end{array}$ & Lindong, Dwards, Dennis & $\begin{array}{c}\text { Estudo quantitativo } \\
\text { Instrumento: questionário }\end{array}$ & $\begin{array}{c}\text { Falta de conhecimento } \\
\text { sobre doenças sexualmente }\end{array}$ \\
\hline
\end{tabular}


RELACult - Revista Latino-Americana de Estudos em Cultura e Sociedade

Revista Latinoamericana de Estudios en Cultura y Sociedad | Latin American Journal of Studies in Culture and Society V. 06, $\mathrm{n}^{\mathrm{o}}$ 01, jan.-abr., 2020, artigo $\mathrm{n}^{\circ}$ 1631 | claec.org/relacult |e-ISSN: 2525-7870

\begin{tabular}{|c|c|c|c|}
\hline $\begin{array}{c}\text { Considering the } \\
\text { Influence of Gender on } \\
\text { HIV Prevention } \\
\text { Programs for Young } \\
\text { Adults in an Urban }\end{array}$ & $\begin{array}{l}\text { e Fajobi (2017). } \\
\text { Pubmed, Inglês }\end{array}$ & $\begin{array}{c}\text { Amostra: } 365 \text { estudantes da } \\
\text { Universidade Americana no } \\
\text { nordeste dos EUA. }\end{array}$ & $\begin{array}{l}\text { transmissíveis; uso de } \\
\text { álcool e drogas ilícitas; não } \\
\text { uso de preservativo }\end{array}$ \\
\hline $\begin{array}{c}\text { Conducta sexual y } \\
\text { realización de la prueba } \\
\text { del virus de la } \\
\text { inmunodeficiencia } \\
\text { humana en jóvenes que } \\
\text { estudian en la } \\
\text { universidad en Cuzco/ } \\
\text { Perú }\end{array}$ & $\begin{array}{c}\text { Bermúdez, Ramiro, Teva, } \\
\text { Ramiro-Sánchez } \\
\text { e Buela-Casal (2017). } \\
\text { BVS Psi, espanhol }\end{array}$ & $\begin{array}{c}\text { Estudo quantitativo } \\
\text { Instrumento: questionário } \\
\text { Amostra:1343 estudantes de } \\
\text { universidades públicas e } \\
\text { privadas de Cuzco/ Peru }\end{array}$ & $\begin{array}{l}\text { Não uso de preservativos; } \\
\text { consumo de álcool e drogas } \\
\text { antes das relações sexuais; } \\
\text { baixo conhecimento sobre } \\
\text { HIV; poucas testagens }\end{array}$ \\
\hline $\begin{array}{l}\text { Jovens universitários e o } \\
\text { conhecimento acerca das } \\
\text { infecções sexualmente } \\
\text { transmissíveis }\end{array}$ & $\begin{array}{c}\text { Fonte, Spindola, Francisco, } \\
\text { Sodré, André e Pinheiro } \\
\text { (2018). } \\
\text { SciELO, português }\end{array}$ & $\begin{array}{c}\text { Estudo quantitativo } \\
\text { Instrumento: questionário } \\
\text { Amostra: } 768 \text { estudantes da } \\
\text { Escola Anna Nery/RJ/ } \\
\text { Brasil }\end{array}$ & $\begin{array}{l}\text { Baixo conhecimento das } \\
\text { ISTs; preconceito } \\
\text { e estigma }\end{array}$ \\
\hline $\begin{array}{c}\text { Comportamientos y } \\
\text { prejuicios de los jóvenes } \\
\text { con relación al } \\
\text { VIH/Sida: un estudio } \\
\text { cualitativo con jóvenes } \\
\text { universitarios } \\
\text { nicaragüenses }\end{array}$ & $\begin{array}{c}\text { Pérez-Pérez, Morón- } \\
\text { Marchena e Cobos-Sanchiz } \\
\text { (2015). } \\
\text { SciELO, espanhol }\end{array}$ & $\begin{array}{c}\text { Estudo qualitativo } \\
\text { Instrumento: entrevista } \\
\text { Amostra: } 16 \text { estudantes da } \\
\text { Universidade de Chontales, } \\
\text { na Costa Rica/ Nicarágua }\end{array}$ & $\begin{array}{c}\text { Falta de informação sobre } \\
\text { doenças sexualmente } \\
\text { transmissíveis; machismo } \\
\text { influenciando o não uso de } \\
\text { preservativo; falta de } \\
\text { diálogo entre jovens e } \\
\text { família }\end{array}$ \\
\hline
\end{tabular}

Fonte: Desenvolvido pela autora

Todos os artigos analisados trouxeram dados e afirmações sobre a importância de se realizar campanhas no meio universitário, a partir do conhecimento que os alunos apresentaram sobre fatores de risco e sobre a necessidade de se realizar ações, tais como campanhas curtas. Ainda, afirmou-se que é necessário que se utilize de pessoas influentes, com visibilidade entre a população que se pretende atingir, com intuito de alcançar uma maior difusão de informações sobre prevenção.

Ademais, em Fonte et al. (2018), o estudo abordou os comportamentos de risco entre estudantes e afirmou que o aumento da probabilidade de um adulto jovem se infectar pelo HIV está associado ao baixo conhecimento das infecções sexualmente transmissíveis. A universidade foi considerada como um espaço de articulação intersetorial, para promover mobilizações sociais de enfrentamento às infecções sexualmente transmissíveis e outros agravos. Segundo esses autores, o meio universitário é aonde os jovens buscam conhecimento e novas experiências. É um contexto que poderá os aproximar de fatores que possam torná-los mais vulneráveis, tendo em vista que a pressão dos pares pode levar ao aumento da probabilidade de vivenciarem atitudes de risco, ou seja, se envolverem em relações sexuais casuais sem o uso de preservativo. Além deste, existem ainda outros fatores relevantes, como o consumo de álcool e outras drogas. 
A vulnerabilidade do jovem pode ainda ser acrescida se este não teve acesso à educação sexual em casa ou na escola durante os ensinos fundamental e médio. Na pesquisa realizada em Cuzco, foi observado que existia uma baixa percepção sobre os possíveis riscos de infecção pelo HIV entre os jovens participantes, apontando a necessidade de intervenções na área da prevenção. O conhecimento dos estudantes em relação às infecções sexualmente transmissíveis possuía lacunas, justificando a importância de ações de educação em saúde no período inicial da graduação (BERMÚDEZ et al., 2017).

Existe ainda a necessidade de as famílias conversarem abertamente com seus jovens sobre sexo e sexualidade, pois, por diversos motivos, sejam eles culturais ou religiosos, esse diálogo não ocorre e, por muitas vezes, são considerados assuntos proibidos. Em casa, tais temas de interesse dos jovens não são permitidos nem discutidos e desse modo, as universidades passam a ser vislumbradas pelos estudantes como um lugar de liberdade e de possibilidade de fala, pois eles se sentem livres para conversarem e se manifestarem. Nesse ambiente mais acolhedor, fala-se sobre relacionamentos, relação sexual, afinidades, grupos sociais, doenças e métodos contraceptivos, de modo natural e diversificado (BERMÚDEZ et al., 2017).

Os estudos de Bermúdez et al. (2017), Pérez-Pérez et al. (2015), Fonte et al. (2018), Lindong et al. (2017), Fu et al. (2018) e Oliveira et al. (2017) assinalaram que havia uma dificuldade de se falar abertamente sobre sexualidade, fato que impacta diretamente na falta de informação sobre as doenças e como evitá-las. Isso porque valores culturais e religiosos podem influenciar uma sociedade, tendo em vista que as práticas de risco estão relacionadas à falta de informação e de consciência entre a juventude.

Além dessa falta de diálogo, o machismo também tem sido uma das influências do não uso de preservativos nas relações sexuais. Na falta do uso das camisinhas, masculina e feminina, as mulheres ficam em situação de vulnerabilidade. Tal situação ocorre também pelo fato de as pessoas confiarem em seus parceiros, ou ainda pela percepção que o preservativo diminui o prazer sexual, conforme é apresentado por Pérez-Pérez et al. (2015). As mulheres, quando não faziam uso do preservativo, confiavam na fidelidade dos parceiros. Ademais, o machismo acabava por fazer com que elas perdessem a capacidade de tomada de decisão sobre a prevenção no momento da relação sexual, já que seus companheiros impunham o não uso do preservativo com a justificativa do não prazer, principalmente o masculino.

Num modelo machista e patriarcal, quem decide o que vai ser feito na hora do sexo é o homem, já que existe uma cultura de privilégio para o prazer masculino, o qual é colocado em primeiro lugar e como mais importante do que o prazer da mulher. Há ainda uma situação 
cultural, perpetuada há décadas, em que o homem tem o controle da casa, da mulher e da intimidade de ambos, tendo ele a palavra final sobre quando, onde e se vão utilizar ou não métodos contraceptivos ou preservativos.

À vista disto, é necessário responder duas questões que emergiram dos estudos, tais como: (1) por que as mulheres, mesmo tendo mais conhecimento, são as que menos utilizavam preservativos?; (2) quais os motivos dessa ocorrência, se é uma questão cultural ou por imposição do machismo, se é uma escolha pessoal ou outros fatores de gênero?

As pesquisas apresentaram que as mulheres eram as que menos realizavam a testagem e não possuíam o hábito de usar preservativos nas relações sexuais, podendo assim vir a descobrir que foram infectadas pelo vírus HIV em uma possível gravidez, quando derem início ao pré-natal. Todavia, esse é um momento crítico para se diagnosticar a soropositividade, já que o HIV pode ser transmitido verticalmente, da mulher gestante para o bebê. Outro aspecto importante observado nessa revisão, é que a baixa procura pela testagem sorológica estava vinculada ao medo de saber o resultado, caso ele fosse positivo, por ser o causador de situações como o preconceito, o estigma e a discriminação tanto da família, como por amigos e colegas.

Outros fatores que colocam os universitários em situação de vulnerabilidade é o uso de álcool e outras drogas, além de comportamentos sexuais de risco, como o não uso de preservativo, sendo que os jovens universitários possuíam baixo conhecimento em relação às infecções sexualmente transmissíveis. Entre esses fatores, o uso de álcool sempre foi identificado como um comportamento mais frequente em homens. Contudo, estudos recentes mostraram que as mulheres adultas jovens tendem a consumir bebidas alcoólicas igual ou mais que os rapazes, quando em ambientes mistos quanto ao gênero (LINDONG et al., 2017). Tal fator evidência a importância de ações de educação em saúde, visando promover o conhecimento que possibilite aos jovens uma compreensão adequada sobre o uso de métodos preventivos, além de trabalhos que visem a redução de danos quanto ao uso de álcool e outras drogas.

Um fator importante a ser destacado e analisado nos artigos de Bermúdez et al. (2017) e Fu et al. (2018), é que havia uma baixa quantidade de testagens sendo realizadas por esse grupo populacional. Assim, os adultos jovens universitários se expõem aos riscos, mas não fazem testes para saberem se estão ou não infectados pelo HIV. De acordo com Fu et al. (2018), alguns motivos para a não realização do teste, na perspectiva dos estudantes, são: o medo de saber se estão infectados pelo HIV ou por preferirem não saber acerca da infecção, assim como a falta de discussão sobre o HIV no meio social em geral. 
$\mathrm{O}$ artigo ressalta ainda que, aqueles estudantes universitários que tinham atitudes consideradas menos discriminatórias e que possuíam maior percepção de risco de infecção pelo HIV, estavam mais propensos a realizar os exames que identificam a infecção. Fu et al. (2018) apresentam três recomendações para que se estimule os estudantes a procurarem os centros de testagem: 1) realizar intervenções de educação em saúde, para que se reduza o estigma e a discriminação, informando os locais em que é possível se realizar o teste; 2) treinar voluntários para atenderem em um centro de testagem, e que esse se localize no mesmo local da universidade; 3) promover cooperação entre vários setores e departamentos da universidade, comunidade e o governo, em ações de prevenção e controle do HIV/aids.

Pode-se inferir também pelos estudos que, os jovens com maior conhecimento relacionados ao HIV eram os que mais se disponibilizavam a realizar o teste, sendo que o estigma e a discriminação eram os principais motivos para que as taxas de testagem voluntárias fossem baixas. Tais fatores podem levar também ao início tardio do tratamento antirretroviral, causando ainda mais danos à saúde.

No que se refere aos aspectos sociais, a média de idade dos alunos das instituições universitárias estudadas variou entre 19 e 22 anos, sendo que a maioria se declarou solteira e a população feminina era maioria nas instituições de ensino superior. Segundo Pérez-Pérez et al. (2015), o ambiente universitário é composto predominantemente por jovens e tem-se observado condutas negativas de saúde durante o período acadêmico, que são reflexos das novas experiências que antes eram proibidas ou limitadas por parte dos familiares.

Esses fatos ocorriam pela necessidade de buscar amizades e de se adaptar a novas rotinas, compromissos e responsabilidades, além de quererem se enquadrar no meio social acadêmico. De acordo com o estudo, todos esses aspectos levavam os jovens a uma maior vulnerabilidade pois possuíam comportamentos que os colocavam em risco. É preciso levar em consideração também a realidade de que inúmeros universitários buscavam festas e eventos com o intuito de descontraírem e socializarem, o que pode levar ao aumento da probabilidade de vivenciarem atitudes de risco. Tal fator evidência a importância de ações de educação em saúde, visando promover o conhecimento que possibilite a eles uma compreensão adequada sobre a adoção de métodos preventivos.

Após o estudo dos artigos, fica claro que mudanças nas estratégias de prevenção ainda devem ser realizadas, para que os países consigam alcançar a proposta das Nações Unidas, sendo a meta denominada "90-90-90" onde 90\% das pessoas infectadas estejam diagnosticadas, que $90 \%$ delas tenham acesso ao tratamento antirretroviral e que $90 \%$ delas tenham carga viral indetectável até 2020 (BRASIL, 2017). Segundo a ONU, uma vez 
alcançado o objetivo proposto para 2020, a nova meta será "95-95-95" em 2030, sendo necessário evoluir os métodos de prevenção da doença. A partir de pesquisas focadas no tema HIV e aids, amplia-se o campo de visão e entendimento sobre a área, possibilitando uma maior capacitação na hora de se realizar pesquisas e campanhas, tão necessárias atualmente, perante a situação da saúde dos adultos jovens universitários no Brasil e no mundo.

\section{Considerações Finais}

Pode-se concluir que o objetivo quanto a analisar artigos recentes que versavam sobre estudos empíricos voltados para fatores de risco em jovens universitários foi atingido, pois as publicações identificadas revelaram que os adultos jovens possuíam lacunas no conhecimento sobre as ISTs, além de outras vulnerabilidades. Observou-se que aqueles que estudavam nas áreas de saúde eram, de modo geral, os que mais compreendiam sobre prevenção do HIV e outras ISTs, sendo em sua maioria mulheres.

Conclui-se ainda sobre a necessidade de que haja nas universidades, estratégias de intervenção para que a comunidade acadêmica possa ter maior conhecimento sobre essas questões de saúde pública, além da oferta gratuita do teste de sorologia para o HIV e outras infecções sexualmente transmissíveis. É necessário também conhecer de modo mais abrangente o comportamento sexual desses jovens, para que se possa realizar campanhas estratégicas, bem dirigidas e focadas, visando reduzir a vulnerabilidade dessa população, respeitando a diversidade existente no meio acadêmico.

Pode-se afirmar que os artigos estavam em consonância, quando assinalaram que esses locais devem estar preparados para realizar os encaminhamentos necessários nos casos de sorologia positiva, para que o tratamento seja iniciado o mais rápido possível. Além disso, as instituições devem informar os locais onde ocorrem a oferta da profilaxia pós-exposição sexual (PEP) ao vírus HIV, como estratégia de prevenção, tendo em vista que ela precisa ser administrada até 72 horas após a pessoa ser exposta ao risco, tal como preconiza o Ministério da Saúde no Manual da Prevenção Combinada (BRASIL, 2017).

É possível compreender ainda que os comportamentos diferenciados referentes às questões de gênero são permeados por questões culturais de cada localidade. No caso do Brasil, por ser um país de tamanho continental e as cinco regiões possuírem culturas e características peculiares, é preciso trabalhar com temas que sejam sensíveis a cada contexto cultural. Todavia, independente do país que esteja realizando uma campanha, é necessário que essas características sejam respeitadas, quando se propõe métodos de prevenção de agravos e 
promoção da saúde. Buscam-se estratégias que viabilizem os direitos e o respeito às diversidades das populações, às denominadas minoritárias, no princípio da equidade.

Para tanto, é necessário adaptar as intervenções para atender às especificidades de cada população, para que se alcance índices de prevenção que possibilitem um aumento na qualidade de vida dos estudantes universitários, sendo importante conhecer os costumes, crenças e atitudes, pois até mesmo o uso ou não uso de preservativos perpassam todas essas questões. A universidade, como instituição formadora, tem grande importância no contexto social e das políticas públicas, pois é nela que pesquisas são realizadas e onde o pensamento se constrói criticamente, sendo capaz, assim, de transformar uma sociedade por meio do conhecimento.

O jovem é parte de uma população que busca entendimento e necessita que o diálogo esteja presente em seu cotidiano, que tenha esclarecimentos sobre o tema HIV, além de que os profissionais que atendem essa população possam ter um olhar mais específico e pontual, onde a saúde não se caracterize pela ausência de doença, mas sim pela qualidade de vida, tendo garantidos os direitos como: saúde, educação, moradia, lazer e segurança (CZERESNIA, 2009). Muitos são os desafios a serem enfrentados para que a população tenha suas demandas atendidas. Assim, para que isso ocorra, é necessário que se trabalhe em redes, com intuito de garantir o acesso resolutivo e efetivo na redução de desigualdades e de danos, que se dá a partir das relações primárias entre familiares, de vizinhança ou comunidade, onde as ligações ocorrem por afinidades, afeto, solidariedade e cooperação.

Existem ainda as redes de serviços público-institucionais, cuja estrutura governamental é direcionada ao atendimento dos direitos positivados por meio de programas e serviços desenvolvidos pelas políticas públicas, assim como as redes sociocomunitárias, organizadas no espaço da comunidade, quando as políticas sociais não são efetivadas para atender demandas coletivas. Ademais, existem as redes compostas por serviços privados e as redes sociais, no qual se organizam e promovem a articulação entre seus membros, para que as políticas públicas possam atender a população e suas especificidades (LOLIS; MOREIRA, 2016).

Os artigos utilizados na revisão de literatura mencionaram a necessidade constante de se realizar educação em saúde para estudantes e comunidade universitária como um todo. Além disso, concluiu-se que é importante que ocorra a inclusão de uma disciplina que trate do tema HIV/aids e outras infecções sexualmente transmissíveis, tendo em vista que ela poderia contribuir no aumento do conhecimento e assim, diminuir o estigma dessas doenças. Concluise ainda que existe a necessidade de se ter na universidade mais informação sobre prevenção 
de agravos e promoção de saúde, assim como uma divulgação dos locais onde se poderia realizar a testagem e a distribuição de preservativos masculinos e femininos gratuitamente.

Urge que as universidades disponibilizem informações a respeito dos locais de referência para o tratamento e acompanhamento de infecções sexualmente transmissíveis, além da formulação de estratégias que envolvam a participação dos estudantes, onde eles sejam treinados para realizar o acolhimento, possibilitando assim uma maior interação com a comunidade acadêmica em toda a sua diversidade. Uma estratégia possível para as universidades seria, por exemplo, incentivar a educação por pares, envolvendo a representatividade estudantil, em especial os centros e diretórios acadêmicos, para desenvolvimento de estratégias de prevenção e capacitação dos próprios estudantes. Dessa forma, eles atuariam como agentes promotores de saúde e protagonistas no delineamento de estratégias para a comunidade discente.

Outra estratégia necessária é o envolvimento do corpo docente com ações de prevenção, procurando fomentar o interesse dos estudantes sobre o HIV e outros aspectos que podem afetar a saúde. Tais ações podem envolver a inserção dos temas em disciplinas, a realização de seminários, oficinas de prevenção, campanhas de promoção da saúde, entre outras atividades. É fundamental que universidades assumam o compromisso institucional de promover saúde, conforme orientado pelas OMS, desde a década de 1990, por meio de estratégia das Universidades Promotoras de Saúde (MOURA; RODRIGUES, 2018).

A universidade também pode fomentar pesquisas que visem conhecer as necessidades da própria comunidade para delinear programas que atendam às demandas emergentes. Finalmente, após o apontamento para os fatores de risco para infecção pelo HIV, sugere-se que outros estudos procurem identificar os fatores de proteção e estratégias já desenvolvidas com sucesso no contexto acadêmico, com intuito de se continuar fortalecendo o protagonismo das universidades como espaços promotores de saúde.

\section{Referências}

AMARAL, R. C. Soropositividade para HIV / aids e Características Sóciocomportamentais em Adolescentes e Adultos Jovens. Revista Pesquisa e Saúde, São Luís, v. 8, p. 108-113, mai/ago, 2017.

BERMÚDEZ, M. P. et al. Conducta sexual y realización de la prueba del virus de la inmunodeficiencia humana en jóvenes que estudian en la universidad en Cuzco/Perú. Gaceta Sanitaria, Elsevier, Granada, v. 32, p. 223-229, 2018. 
BRASIL. Recomendações Para Terapia Antirretroviral em Adultos e Adolescentes Infectados pelo HIV. Ministério da Saúde - Programa Nacional de DST e aids, Brasília, 2008.

Programa Conjunto das Nações Unidas Sobre HIV/aids - Retrospectivas do

UNAIDS no Brasil. Ministério da Saúde, Brasília, 2017.

Secretaria de Vigilância em Saúde: Departamento de Vigilância, Prevenção e Controle das Infecções Sexualmente Transmissíveis, do HIV/aids e das Hepatites Virais. Prevenção combinada do HIV: Bases conceituais para profissionais, trabalhadores(as) de saúde. Ministério da Saúde, Brasília, 2017.

Departamento de Vigilância, Prevenção e Controle das Infecções Sexualmente Transmissíveis, do HIV/aids e das Hepatites Virais. Ministério da Saúde, Brasília, 2018.

Lei n $^{\circ} 8.069$, de 13 de julho de 1990. Dispõe sobre o Estatuto da Criança e do Adolescente e dá outras providências. Casa Civil. Disponível em: <http://www.planalto.gov.br/ccivil_03/LEIS/L8069.htm ECA>. Acesso em: 13 de junho de 2019.

CARVALHO, S. R; GASTALDO, D. Promoção à Saúde e Empoderamento: Uma Reflexão a Partir das Perspectivas Crítico-Social Pós-Estruturalista. Ciência \& Saúde Coletiva, Rio de Janeiro, v. 13, p. 2029-2040, 2008.

CZERESNIA, D.; FREITAS, C. Promoção da Saúde: Conceitos, Reflexões, Tendências. Rio de Janeiro: Editora Fiocruz, 2009.

FONTE, V. R. F. et al. Young University Students and The Knowledge About Sexually Transmitted Infections. Escola Anna Nery, Rio de Janeiro, EEAN, v. 22, p. 1-7, 2018.

FU, G. et al. The Prevalence of and Factors Associated with Willingness to Utilize HTC Service Among College Students in China. Public Health, Hubei Province, BMC, v. 18, p. 1$10,2018$.

LINDONG, I. et al. Similarities and Differences Matter: Considering the Influence of Gender on HIV Prevention Programs for Young Adults in an Urban HBCU. International Journal of Environmental Research and Public Health, Baltimore, MDPI, v. 14, p. 1-10, 2017.

LOLIS, D.; MOREIRA, F. Trabalho em Rede: Um Olhar Sobre a Garantia da Integralidade dos Direitos da Criança e do Adolescente a Partir da Política de Saúde. Serviço Social em Revista, Londrina, UEL, v. 19, n.1, p. 109-130, jul./dez., 2016.

MOURA, L. B. A (Org.); RODRIGUES, N. S. (Org.). Universidade Promotora de Saúde: O Percurso da Faculdade de Ciências da Saúde - Universidade de Brasília. Brasília: Universidade de Brasília, 2018.

NODIN, N.; DIÉGUEZ, A.C.; LEAL, I.P. Comportamentos Sexuais de Risco e Preventivos Masculinos: Resultados de uma Amostra Recolhida através da Internet em Portugal. Saúde Social, São Paulo, v.24, n.2, p. 607-619, 2015. 
OLIVEIRA, A. et al. Impacto de um Programa de Intervenção Educativa Nos

Comportamentos Sexuais de Jovens Universitários. Revista de Enfermagem Referência, Coimbra, série IV, n. 13, p. 71-82, abr./mai./jun., 2017.

LOBATO, A. (Org.). Manual de Saúde e Sexualidade de Adolescentes. Construindo Equidade no SUS. Brasília: OPAS, MS, 2017.

PÉREZ-PÉREZ, I., MORÓN-MARCHENA, J. A.; COBOS-SANCHIZ, D. Comportamientos y Prejuicios de los Jóvenes con Relación al VIH/Sida: Un Estudio Cualitativo con Jóvenes Universitarios Nicaragüienses. Población y Salud en Mesoamérica, Costa Rica, v. 13, n. 1, p. 1-28, jul. /dic., 2015.

UNIVERSIDADE DE BRASÍLIA. Anuário. Brasília: Decanato de Planejamento e Orçamento. Universidade de Brasília, Brasília, 2018. Disponível em: <http://www.unb.br unb@unb.brdpodai@unb.br>. Acesso em 23 de maio de 2019. 